О. М. Паценко

Національний науковий центр «Інститут метрології», Харків, Україна

\title{
ОЦІНЮВАННЯ НЕВИЗНАЧЕНОСТІ ВИМІРЮВАННЯ ТВЕРДОСТІ МЕТАЛІВ МЕТОДОМ БРІНЕЛЛЯ
}

\begin{abstract}
Метою статті $є$ розробка процедури оцінювання невизначеності вимірювань твердості металів методом Брінелля. Результати. Проаналізовано основні методи вимірювання твердості. Розглянуто особливості вимірювання твердості металів методом Брінелля та наведені основні джерела невизначеності. Розроблена процедура оцінювання невизначеності вимірювань твердості металів методом Брінелля та наведений приклад оцінювання невизначеності. Проведена валідація розробленої процедури методом Монте-Карло.

Ключов і слов а: твердість метала, метод Брінелля, невизначеність вимірювань, бюджет невизначеності, метод Монте-Карло.
\end{abstract}

\section{Вступ}

Вимірювання твердості є найпоширеніші з усіх механічних випробувань, як при дослідженнях, так і при контролі якості продукції в виробничих умовах. Знаючи твердість можна швидко знайти межу міцності і текучості матеріалу, що дуже важливо для прикладних інженерних задач [1].

Механічні властивості зумовлюють поведінку виробу під впливом зовнішніх навантажень, які можуть значно змінюватися залежно від умов експлуатації.

Використання методів механічних випробувань на твердість дозволяє:

- випробувати малі об'єми металу;

- проводити механічні випробування, коли інші способи використати неможливо;

- випробувати матеріали без руйнування;

- використовувати зразки 3 попередньою обробкою малої ділянки поверхні матеріалу;

- визначати твердість окремих структурних складових або окремих шарів матеріалу;

- вимірювати твердість безпосередньо на працюючому устаткуванні;

- встановлювати аналітичний зв'язок з даними інших випробувань.

Для визначення твердості використовуються статичні та динамічні методи [2]. Найбільш поширеними $є$ статичні методи, при яких навантаження на індентор прикладають плавно й повільно, час витримування під навантаженням регламентується стандартами на методи проведення випробувань, тому вони є найбільш точними. До статичних методів відносяться методи Брінелля, Роквелла та Віккерса [3].

На підприємствах найбільш широко використовується метод Брінелля, оскільки він не потребує ідеальної чистоти поверхні, та знаючи твердість по Брінеллю можна швидко знайти межу міцності та текучості матеріалу, що дуже важливо для прикладних інженерних задач [4].

Вимірювання твердості здійснюється в випробувальних лабораторіях, які $\epsilon$ акредитованими на виконання вимог стандарту ISO/IEC 17025:2017 [5]. Цей стандарт законодавчо закріпив необхідність наявності процедур оцінювання невизначеності вимірювань (НВ), які були проведені в акредитованих лабораторіях.

Метою цієї статті є розробка процедури оцінювання невизначеності вимірювань твердості металів методом Брінелля.

\section{Аналіз процедури вимірювань твердості та основних джерел невизначеності вимірювань}

При визначенні твердості за методом Брінелля сталева кулька діаметром (D) вдавлюється у випробуваний зразок під дією навантаження (P), прикладеного на період визначеного часу (рис. 1).

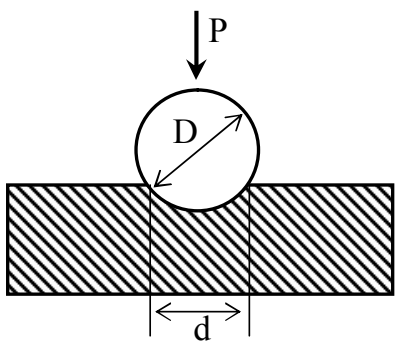

Рис. 1. Схема методу Брінелля

Число твердості по Брінеллю НВ дорівнює відношенню навантаження Р (Н) до площі кулькової поверхні відтиску S (мм²) і розраховують за формулою:

$$
H B=\frac{P}{S}=\frac{2 P}{\pi D\left(\mathrm{D}-\sqrt{D^{2}-d^{2}}\right)},
$$

де D - діаметр кульки, мм; d - діаметр відтиску, мм.

Діаметр відтиску визначається за допомогою вимірювального мікроскопа в сотих долях міліметра як середнє арифметичне 3 двох вимірювань взаємно перпендикулярних діаметрів.

Для підвищення точності вимірювання твердості експеримент повторюють багаторазово 3 оцінюванням середнього арифметичного значень твердосTi.

Параметри, які є джерелами невизначеності при вимірюванні твердості, наведені в табл. 1 і розділені на групи відповідно до їх походження: випробуваний зразок; твердомір; довкілля;оператор. 
Таблиия 1 - Параметри які впливають на невизначеність вимірювання твердості

\begin{tabular}{|c|c|c|}
\hline \multicolumn{2}{|c|}{ Група } & Джерело невизначеності \\
\hline \multirow{6}{*}{\multicolumn{2}{|c|}{1 Зразок, що випробовується }} & Занадто мала товщина зразка \\
\hline & & Жорсткість опори (столика) \\
\hline & & Занадто груба структура зерна \\
\hline & & Шорсткість поверхні \\
\hline & & Неоднорідний розподіл твердості \\
\hline & & Чистота поверхні \\
\hline \multirow{14}{*}{ 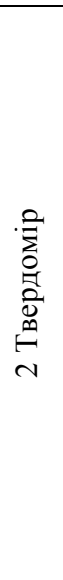 } & \multirow{3}{*}{ а) корпус приладу } & Втрата на тертя \\
\hline & & Пружна деформація \\
\hline & & Несоосність шпинделя індентора \\
\hline & \multirow{4}{*}{ б) система вимірювання діаметра відбитка } & Похибка індикації \\
\hline & & Недостатнє розширення \\
\hline & & Числова апертура лінзи або освітлювача \\
\hline & & Неоднорідне освітлення відбитка \\
\hline & \multirow{4}{*}{ в) система прикладання навантаження } & Відхилення від номінальних сил \\
\hline & & Відхилення від тимчасових інтервалів циклу випробування \\
\hline & & Прикладання навантаження \\
\hline & & Перевантаження випробувальних сил \\
\hline & \multirow{3}{*}{ г) індентори } & Відхилення від ідеальної форми \\
\hline & & Пошкодження \\
\hline & & Деформація під навантаженням \\
\hline \multirow{2}{*}{\multicolumn{2}{|c|}{3 Навколишнє середовище }} & Температурне відхилення або дрейф \\
\hline & & Вібрація і удари \\
\hline \multirow{2}{*}{\multicolumn{2}{|c|}{4 Оператор }} & Неправильний вибір методу \\
\hline & & Помилки при роботі, зчитуванні, оцінці результатів \\
\hline
\end{tabular}

\section{Процедура оцінювання невизначеності вимірювань}

Процедура розроблена згідно з Настановою 3 оцінювання невизначеності вимірювань (GUM) [6] та складається з наступних операцій.

1. Запис моделі (рівняння) вимірювань. При вимірюванні навантаження у Ньютонах та проведенні n-разових випробувань твердості, модельне рівняння має такий вигляд:

$$
H B=\frac{1}{n} \sum_{i=1}^{n}\left[\frac{0,10197162 \cdot 2 P}{\pi D^{2}\left(1-\sqrt{1-\left(d_{i} / D\right)^{2}}\right)}\right]+\varepsilon(H B),
$$

де константа 0,10197162=1/9,80665 - коефіцієнт перерахування з кгс у Н; $d_{i}$ - діаметр відтиску при i-му випробуванні; $\varepsilon(H B)$ - поправка на випадкову похибку вимірювання твердості.

2. Оцінювання вхідних величин._Вимірювання твердості проводились за допомогою робочого еталона твердоміра-компаратора ТШ-2М, який відтворює значення тиску $\widehat{P}=30000$ кгс. В якості індентора в еталоні використовується сталева сфера діаметром $\hat{D}=10$ мм.

Результати вимірювання діаметрів відтисків $d_{1}$ i $d_{2}$ у протилежних напрямках та середні значення цих діаметрів $d$ наведені у табл. 2 .

Оскільки поправка на випадкову похибку вимірювання твердості $є$ центрованою величиною, іiі значення $\widehat{\varepsilon}(H B)$ дорівнює нулю.
Таблиця 2 - Результати вимірювання діаметрів відтисків

\begin{tabular}{|c|c|c|c|}
\hline $\begin{array}{c}\text { № } \\
\text { випробування }\end{array}$ & $\hat{d}_{1}, \mathbf{\text { мм }}$ & $\hat{d}_{2}, \mathbf{\text { мм }}$ & $\hat{d}, \mathbf{, м м}$ \\
\hline 1 & 2,94 & 2,94 & 2,94 \\
\hline 2 & 2,98 & 2,96 & 2,97 \\
\hline 3 & 2,96 & 2,94 & 2,95 \\
\hline 4 & 2,94 & 2,96 & 2,95 \\
\hline 5 & 2,96 & 2,96 & 2,96 \\
\hline
\end{tabular}

3. Обчислення числового значення вимірюваної величини здійснюється за формулою:

$$
\begin{gathered}
\overline{H B}=\frac{1}{n} \sum_{i=1}^{n} H B_{i}+\widehat{\varepsilon}(\mathrm{HB}), \\
H B_{i}=\frac{0,10197162 \cdot 2 \widehat{P}}{\pi \widehat{D}^{2}\left(1-\sqrt{1-\left(\hat{d}_{i} / \widehat{D}\right)^{2}}\right)} .
\end{gathered}
$$

3 урахуванням наведених значень вхідних величин, розраховуємо значення $H B_{i}$ (табл. 3).

Таблиця 3 - Результати вимірювання твердості

\begin{tabular}{|c|c|}
\hline $\begin{array}{c}\text { № } \\
\text { випробування }\end{array}$ & $H B_{i}, \mathbf{H B W}$ \\
\hline 1 & 440,6682 \\
\hline 2 & 431,6059 \\
\hline 3 & 437,6167 \\
\hline 4 & 437,6167 \\
\hline 5 & 434,5961 \\
\hline
\end{tabular}


Середнє значення твердості $\overline{H B}$, яке приймається за результат вимірювання, дорівнює 436,4048HBW.

4. Оцінювання стандартних невизначеностей вхідних величин._Згідно технічних характеристик твердоміра-компаратора ТШ-2М границя похибки навантажень $\delta_{P}$, складає не більше $\pm 1 \%$. Тому стандартна невизначеність типу В відтворення навантаження в припущенні рівномірного закону розподілу цієї похибки буде дорівнювати:

$$
u_{B}(P)=\frac{\hat{P} \cdot \delta_{P}}{100 \cdot \sqrt{3}}=173,21 \text { кгс. }
$$

Згідно з ГОСТ 9012-59 граничний відхил $\theta_{D}$ діаметра кульки від номінального розміру для кульки 10 мм складає $\pm 0,005$ мм. Тому стандартна невизначеність типу В відтворення діаметру кульки в припущенні рівномірного закону розподілу цього відхилення буде дорівнювати:

$$
u_{B}(\mathrm{D})=\theta_{D} / \sqrt{3}=0,002887 \text { мм. }
$$

Вимірювання діаметру відтиску залежить від похибки вимірювального мікроскопа МПБ-3. Згідно його технічних характеристик границя допустимої абсолютної похибки $\theta_{d}$ в діапазоні вимірювання 0 - 3,0 мм складає $\pm 0,012$ мм. Тому стандартна невизначеність типу В вимірювання діаметру відтиску в припущенні рівномірного закону розподілу цієї похибки буде дорівнювати:

$$
u_{B}(\mathrm{~d})=\theta_{d} / \sqrt{3}=0,006928 \mathrm{мм} .
$$

Стандартна невизначеність типу А, яка обумовлена розкидом наведених в табл. 3 значень твердості $H B_{i}$ розраховується як:

$$
u_{A}(\overline{\mathrm{HB}})=\sqrt{\frac{1}{n(n-1)} \sum_{i=1}^{n}\left(\mathrm{HB}_{i}-\overline{\mathrm{HB}}\right)^{2}}=1,5397 \mathrm{HBW} \text {. }
$$

5. Обчислення внесків невизначеностей вхідних величин у невизначеність вимірюваної величини. Для цього спочатку обчислимо коефіцієнти чутливості до відповідних вхідних величин:

$$
\begin{aligned}
\mathrm{c}_{P}(\mathrm{HB})= & \frac{\partial H B}{\partial P}=\frac{0,10197162 \cdot 2}{\pi \bar{D}^{2}\left(1-\sqrt{1-(\bar{d} / \widehat{D})^{2}}\right)}= \\
& =0,01455 \mathrm{HB} \mathrm{W} / \text { кгс; }
\end{aligned}
$$

Таблиия 4 - Бюджет невизначеності

\begin{tabular}{|c|c|c|c|c|c|}
\hline $\begin{array}{c}\text { Вхідні } \\
\text { величини }\end{array}$ & $\begin{array}{c}\text { Значення вхід- } \\
\text { них величин }\end{array}$ & $\begin{array}{c}\text { Стандартні невизначе- } \\
\text { ності вхідних величин }\end{array}$ & $\begin{array}{c}\text { Кількість сте- } \\
\text { пенів свободи }\end{array}$ & $\begin{array}{c}\text { Коефіціснти } \\
\text { чутливості }\end{array}$ & $\begin{array}{c}\text { Внески невизна- } \\
\text { ченості, НВW }\end{array}$ \\
\hline $\mathrm{P}$ & 30000 кгс & 173,205 кгс & $\infty$ & $0,0146 \mathrm{HBW} /$ кгс & 2,519 \\
\hline $\mathrm{D}$ & $10 \mathrm{MM}$ & $0,00289 \mathrm{MM}$ & $\infty$ & $2,038 \mathrm{HBW} / \mathrm{MM}$ & 0,0059 \\
\hline $\mathrm{d}$ & $2,954 \mathrm{mM}$ & $0,00693 \mathrm{MM}$ & $\infty$ & $302,369 \mathrm{HBW} / \mathrm{MM}$ & $-2,095$ \\
\hline$\varepsilon(\mathrm{H})$ & 0 & $1,5397 \mathrm{HBW}$ & 4 & 1 & 1,5397 \\
\hline $\begin{array}{c}\text { Вимірювана } \\
\text { величина }\end{array}$ & $\begin{array}{c}\text { Значення } \\
\text { вимірюваної } \\
\text { величини }\end{array}$ & $\begin{array}{c}\text { Сумарна стандартна } \\
\text { невизначеність }\end{array}$ & $\begin{array}{c}\text { Ефективна } \\
\text { кількість степе- } \\
\text { нів свободи }\end{array}$ & $\begin{array}{c}\text { Коефіціснт } \\
\text { охоплення }\end{array}$ & $\begin{array}{c}\text { Розширена } \\
\text { невизначеність }\end{array}$ \\
\hline НВ & $436,4 \mathrm{HBW}$ & 3.62 НВW & 122 & 1,98 & 7.2 НВW \\
\hline
\end{tabular}

$$
\begin{gathered}
\mathrm{c}_{D}(\mathrm{HB})=\frac{\partial H B}{\partial D}=\frac{0,10197162 \cdot 2 P}{\pi \bar{D}^{3} \sqrt{1-(\bar{d} / \bar{D})^{2}}}= \\
=2,0385 \mathrm{HBW} / \mathrm{MM} ; \\
\mathrm{c}_{d}(\mathrm{HB})=\frac{\partial H B}{\partial d}=\frac{-0,10197162 \cdot 2 P d}{\pi D^{4}\left(1-\sqrt{1-(\bar{d} / \bar{D})^{2}}\right)^{2}} \times \\
\times \frac{1}{\sqrt{1-(\bar{d} / \bar{D})^{2}}}=-302,369 \mathrm{HBW} / \mathrm{Mm} ; \\
\mathrm{c}_{\varepsilon}(\mathrm{HB})=\frac{\partial H B}{\partial \varepsilon(\mathrm{HB})}=1 .
\end{gathered}
$$

Тоді внески невизначеностей вхідних величин у невизначеність вимірюваної величини є такими:

$$
\begin{gathered}
\mathrm{u}_{P}(\mathrm{HB})=\mathrm{c}_{P}(\mathrm{HB}) \cdot \mathrm{u}_{B}(\mathrm{P})=2,519 \mathrm{HBW} ; \\
\mathrm{u}_{D}(\mathrm{HB})=\mathrm{c}_{D}(\mathrm{HB}) \cdot \mathrm{u}_{B}(\mathrm{D})=0,0059 \mathrm{HBW} ; \\
\mathrm{u}_{d}(\mathrm{HB})=\mathrm{c}_{d}(\mathrm{HB}) \cdot \mathrm{u}_{B}(\mathrm{~d})=-2,095 \mathrm{HBW} ; \\
\mathrm{u}_{\varepsilon}(\mathrm{HB})=\mathrm{c}_{\varepsilon}(\mathrm{HB}) \cdot \mathrm{u}_{A}(\overline{H B})=1,5397 \mathrm{HBW} .
\end{gathered}
$$

6. Обчислення стандартної невизначеності вимірюваної величини здійснюється за формулою:

$$
\begin{aligned}
\mathrm{u}(\mathrm{HB})=\sqrt{\mathrm{u}_{P}^{2}(\mathrm{HB})}+\mathrm{u}_{D}^{2}(\mathrm{HB})+\mathrm{u}_{d}^{2}(\mathrm{HB})+\mathrm{u}_{\varepsilon}^{2}(\mathrm{HB}) & = \\
& =3,55 \mathrm{HBW} .
\end{aligned}
$$

7. Обчислення розширеної невизначеності здійснюється за формулою:

$$
U(\mathrm{HB})=k \cdot \mathrm{u}(H B),
$$

Де $k$ - коефіцієнт охоплення, який обчислюється як коефіцієнт Стьюдента для ймовірності 0,95 та ефективного числа степенів свободи, яке розраховується по формулі Велча-Саттерсвейта:

$$
v_{\text {eff }}=(n-1) \cdot\left[\frac{\mathrm{u}(H B)}{u_{\varepsilon}(H B)}\right]^{4}=121 \text {. }
$$

В цьому випадку $k=1,98$ та розширена невизначеність $U(H B)$ буде дорівнювати 7,17HBW:

$$
\frac{\text { 8. Запис результату вимірювання }}{\mathrm{HB}=(436,4 \pm 7,2) \mathrm{HBW}, p=0,95 .}
$$

9. Складання бюджету невизначеності наведено в табл. 4. 
Для валідації розробленої методики здійснений розрахунок невизначеності вимірювань методом Монте-Карло за допомогою програми NIST Uncertainty Machine [7]. Гістограма закону розподілу вимірюваної величини наведена на рис. 2.

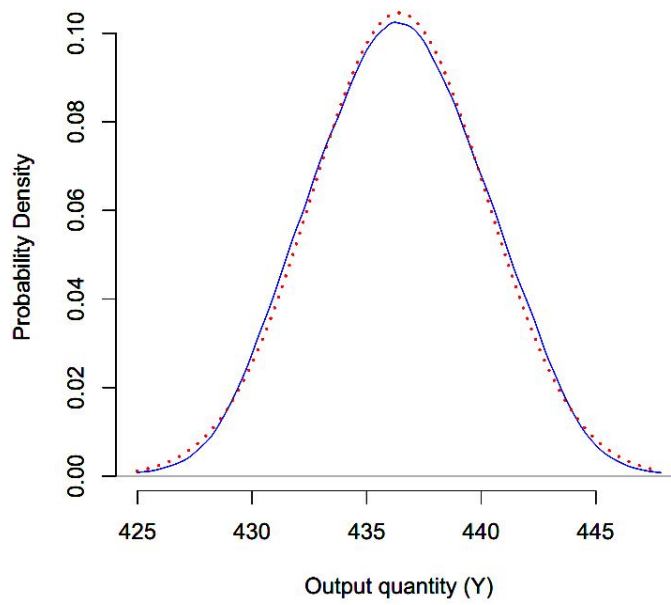

Рис. 2. Результати обчислення методом Монте-Карло

В табл. 5 наведено отримані результати обчислення, якідобре співпадають 3 результатами розрахунку за методом GUM.

\section{Таблиця 5 - Результати обчислення методом Монте-Карло}

\begin{tabular}{|l|c|}
\hline \multicolumn{1}{|c|}{ Параметр } & Значення \\
\hline Значення вимірюваної величини & $436.41 \mathrm{HBW}$ \\
\hline Сумарна стандартна невизначеність & $3.81 \mathrm{HBW}$ \\
\hline Розширена невизначеність & $7.25 \mathrm{HBW}$ \\
\hline
\end{tabular}

\section{Висновки}

1. Розглянуто основні поняття та методи визначення твердості. Надано порівняльну характеристику найбільш популярних методів. Для подальших досліджень обрано метод Брінелля.

2. Розглянуті основні джерела невизначеності вимірювань твердості металу за методом Брінелля. Розроблено процедуру оцінювання невизначеності при вимірюванні твердості за методом Брінелля.

3. Складено бюджет невизначеності як основу для подальшої автоматизації розрахунків. Показано, що основними джерелами невизначеності є відтворення навантаження, вимірювання діаметру відбитку та відтворюваність вимірювань.

4. Для валідації розробленої процедури виконаний розрахунок невизначеності вимірювань методом Монте-Карло. Показано гарний збіг результатів, отриманих обома методами.

\title{
СПИСОК ЛІТЕРАТУРИ
}

1. Методы измерения твердости. Справ. издание / А.Г. Колмаков и др. - М.: Интермет Инжиниринг, 2000. - 128 с.

2. Мартинчук В.П., Полонський Л.Г. Становлення та розвиток методів визначення твердості матеріалів. Технікоісторичний аспект // Весник ХНАДУ / Сб. научн. тр. - Харьков: ХНАДУ, 2009. - Вып. 46. - С. 26-33.

3. Petik, F. The Unification of Hardness Measurement. Paris: BIML, 1991, p. 66-69.

4. ASTM E10 - 12. Standard Test Method for Brinell Hardness of Metallic Materials.

5. ISO/IEC 17025:2017(en). General requirements for the competence of testing and calibration laboratories.

6. Guide to the Expression of Uncertainty in Measurement. Geneva, ISO, 1993. 101 p.

7. The NIST Uncertainty Machine. Avaivable at : https://uncertainty.nist.gov/

Рецензент: д-р техн. наук, проф. І. П. Захаров, Харківський національний університет радіоелектроніки, Харків Received (Надійшла) 15.05.2019 Accepted for publication (Прийнята до друку) 10.07.2019

\section{Оценивание неопределенности измерений твердости металлов методом Бринелля}

\author{
А. Н. Паценко
}

Целью статьи является разработка процедуры оценивания неопределенности измерений твердости металлов методом Бринелля. Результаты. Проанализированы основные методы измерения твёрдости. Рассмотрены особенности измерения твердости металлов методом Бринелля и приведены основные источники неопределенности. Разработана процедура оценивания неопределенности измерений твёрдости металлов методом Бринелля и приведен пример оценивания неопределенности. Проведена валидация разработанной процедуры методом Монте-Карло.

Кл ючевы е сл ов а: твердость металла, метод Бринелля, неопределенность измерений, бюджет неопределенности, метод Монте-Карло.

\section{Evaluation of the uncertainty of measurements of hardness of metals by the Brinell method}

\section{A. Patsenko}

The basic concepts and methods of measuring hardness are analyzed. Comparative characteristics of the most common methods are provided. The features of measuring the hardness of metals by the Brinell method are considered and the main sources of uncertainty are given. A procedure for measurement uncertainty evaluation of metal hardness by the Brinell method has been developed. This procedure includes next steps:modelling the measurement, evaluating input quantities, evaluating the measurand, estimating standard uncertainties of input quantities, calculating the contributions of the measurement uncertainties of input quantities to the uncertainty of the measurand, calculating the combined standard uncertainty, calculating the expanded uncertainty, reporting and recording measurement result. An example of uncertainty evaluation is given. An uncertainty budget has been drawn up as a basis for further automation of calculations. It is shown that the main sources of uncertainty are reproduction of the load, measurement of the diameter of the print and repeatability of measurements. To validate the developed procedure, the calculation of the measurement uncertainty by the Monte Carlo method was performed. Good agreement between the results obtained by both methods is shown.

Keywords: metal hardness, Brinell method, measurement uncertainty, uncertainty budget, Monte Carlo method. 